\title{
University laboratory of biomechanics and sport analytics and engineering in Gdansk as an important science institution
}

\begin{abstract}
Polish scientific biomechanics started in 1920s. This was applied at first to the biomechanics of physical education and sport. Institutional biomechanics in Gdansk started in 1971. Main areas of research of Gdansk center were: 1) human morphology, 2) human kinesiology, 3) muscle mechanics, 4) biomechanics of sport - general approach and many applications to sport disciplines, 5) image methods used for research of movement, 6) sport engineering, 7) biomedical engineering, 8) forensic biomechanics. In 2019 scientists of the Laboratory of Biomechanics and Sport Analytics and Engineering were engaged in the following areas of interest: 1) geometry and inertia of athletes, 2) distribution of velocity along the running track, 3) biomechanics of speed skating, 4) high jumping in athletics, 5) forensic biomechanics. There are altogether about 30 scientific areas developing by the Gdansk sport scientists specializing in biomechanics, analytics, engineering, many of them on the world level including at the best world level.
\end{abstract}

Keywords: body morphology, velocity distribution, speed skating, high jumping, forensic opinions
Volume 4 Issue I - 2020

\author{
Erdmann WS, Aschenbrenner P, Dancewicz- \\ Nosko D, Kowalczyk R, Urbanski R \\ Gdansk University of Physical Education and Sport Gdansk \\ Poland
}

Correspondence: Erdmann WS, Laboratory of Biomechanics and Sport Analytics and Engineering, Gdansk University of Physical Education and Sport Gdansk, Poland, Email wlodzimierz.erdman@awf.gda.pl

Received: December 22, 2019 | Published: January 09, 2020

\section{Introduction}

Biomechanics as a science appeared in Greek Ancient times (Aristotle). ${ }^{1}$ Modern approaches started with the work of Borelli in Italy in the 17th century. ${ }^{2}$ Biomechanics of sport started at the end of the 19th century when Muybridge in the United States and Marey in France presented photographic multiple images of athletes during their movements. ${ }^{3,4}$ In Poland biomechanics started at the first half of the 20th century. This was applied at first to the biomechanics of physical education and sport. In 1921 Piasecki in Poznan wrote on the necessity of analysis of mechanics of movement for physical education major students. His idea was introduced to the curriculum by Kaminski in $1928 .{ }^{5}$ In Warsaw Poplewski (since the half of 1920s) lectured biomechanics for physical education major at the university level. ${ }^{6}$ During the second half of the 20th century especially the following researchers developed biomechanics of sport in Poland (chronologically): Kabsch, ${ }^{7}$ Fidelus ${ }^{8}$ Bober, ${ }^{9}$ Wit, ${ }^{10}$ Dworak. ${ }^{11}$ In 1971 Erdmann (who studied physical education major and then as supported studies machine building major) established the first Biomechanics Laboratory at the College of Physical Education (today: Gdansk University of Physical Education and Sport) in Gdansk. The main areas of research of the Laboratory of Biomechanics, then Department of Biomechanics, Department of Biomechanics and Sport Engineering, and now again Laboratory of Biomechanics and Sport Analytics and Engineering, were: 1) human morphology, especially geometry and inertia, 2) human locomotion, especially technics and tactics of athletes (in athletics, alpine and cross-country skiing, swimming, rowing, handball, football/soccer), 3) kinesiology, 4) muscle mechanics, especially investigations of strength of muscle groups based on measurement of force of dynamometer resistance and its force arm and calculation of muscle group force arm from the length of the body part at which the muscle group acts, 5) biomechanics of sport in general and in many applications to several sport disciplines, 6) image methods used for research of movement from ancient times up to the 21st century, 7) sport engineering, 8) biomedical engineering, 9) forensic biomechanics.

The main publications of the Gdansk center in the forms of monographs, articles, conference presentations, dissertation theses, were: on general biomechanics, ${ }^{12}$ biomechanics of judo, ${ }^{13}$ image methods in sports, ${ }^{14}$ engineering of movement rehabilitation, ${ }^{15}$ geometry and inertia of the human trunk divided onto five parts ${ }^{16-18}$, biomechanics of tactics of alpine skiing, ${ }^{19}$ biomechanics of soccer, ${ }^{20,21}$, biomechanics of high jumping, ${ }^{22}$ biomechanics of tactics of rowing. ${ }^{23}$ In 2019 scientists of the Laboratory of Biomechanics and Sport Analytics and Engineering were engaged in the following areas of interest: 1) geometry and inertia of athletes, 2) distribution of velocity along the running track, 3) biomechanics of speed skating, 4) high jumping in athletics, 5) forensic biomechanics.

\section{Scientific areas developed in 2019}

\section{Geometry and inertia of the human body}

Research activities of geometry and inertia of the human body, especially of athletes, is important scientific problem in the area of anthropology and biomechanics. Body build influences mechanical characteristics of movement since the body creates some resistance overcome by muscle or external forces. For example, length of lower extremities influences stride length, area of body surface perpendicular to the direction of movement acts on air or water resistance, volume of the body is important in buoyancy (Figure 1). Detailed measuring of the body is also necessary for the purpose of orthopedic surgery. Mass of the body is a measure of inertia (resistance) in transversal movement, while moment of inertia (mass and its distance from the axis of rotation) is a measure in rotational movement. These problems were described in a publication in scientific journal ${ }^{24}$ and also as a chapter in monograph published in USA (Figure 2). ${ }^{25}$ 
A

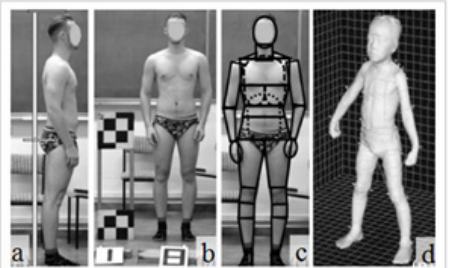

B

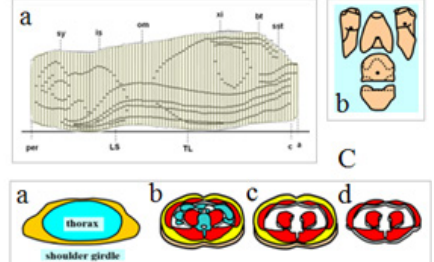

Figure I Examples of illustrations from the article in Acta Physica Polonica A [24]:A - different techniques of obtaining external geometrical dimensions of the body ( $\mathrm{a}$ - anthropometer, $\mathrm{b}$ - photogrammetry, c - modeling, $\mathrm{d}$ - laser use, courtesy of Hamamatsu ); application of computerized tomography (B) for obtaining internal images of layers of the body (a) for trunk parts (b); and their tissues (C) (a - division of a layer onto trunk parts, $b$ - whole layer including bone and digestion tissues, $\mathrm{c}-$ muscle and adipose tissues, $\mathrm{d}-$ muscle tissue).

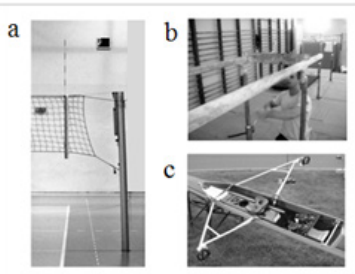

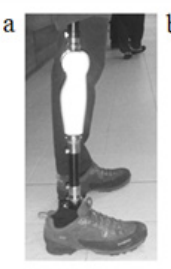

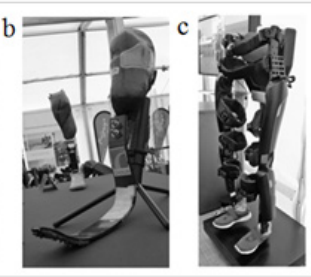

Figure 2 Examples of illustrations from the chapter of the monograph $A$ Closer Look at Biomechanics [25]:A - adaptation of devices of sport engineering for dimensions of the athlete's body: a - volleyball, $b$ - gymnastics, $c$ - rowing; B - devices of orthopaedic engineering which need to be adjusted to the dimensions of patient's body: a - lower leg prosthesis, b - flex-foot, c exoskeleton.

\section{Distribution of velocity along the running track}

Through the last a dozen or so years Erdmann and his collaborators from Gdansk biomechanics performed investigations on movement (distribution of velocity along the distance) in many sport disciplines. It was revealed that during prolonged effort (running, swimming, speed skating, skiing, bicycling) when a world record was obtained or athletes won in prestigious competitions they have specific distribution of velocity. Based on these investigations Erdmann ${ }^{26}$ introduced a biological law which says: in order to win in prolonged effort it is the best to begin very well but to end even better with minimalization of deviations from the velocity trend. Above investigations were aimed at professional athletes. The aim of the next investigations realized since few years, including 2019, by Erdmann, Urbanski and Aschenbrenner, and Dancewicz-Nosko ${ }^{27}$ were investigations of distribution of velocity of fit persons but not engaged in professional sport (students of physical education major). The subjects performed running at the distance of $1200 \mathrm{~m}$ on stadium track with the best time. The most often profile of the velocity had a saddle like shape. Students began faster, then slowed down and before the finish they ran again faster. Next, subjects performed a run on a treadmill with the same average velocity (though diminished according to the stadium velocity at 5 and $10 \%$ ): a) with lowering velocity, b) with steady velocity, c) with rising velocity. All above runs were performed in different days. During the run oxygen consumption by the subjects' organism was measured. It was found the highest volume of oxygen was used during the run with lowering velocity and the lowest volume during rising velocity (with the same average velocity). These findings were especially seen in poorest runners and weak in the best runners. The conclusion was acquired, it is not good idea to begin the run too fast. It is better to begin the run moderate and then to rise velocity with the approaching the finish line (Figures $3 \& 4) .{ }^{28}$

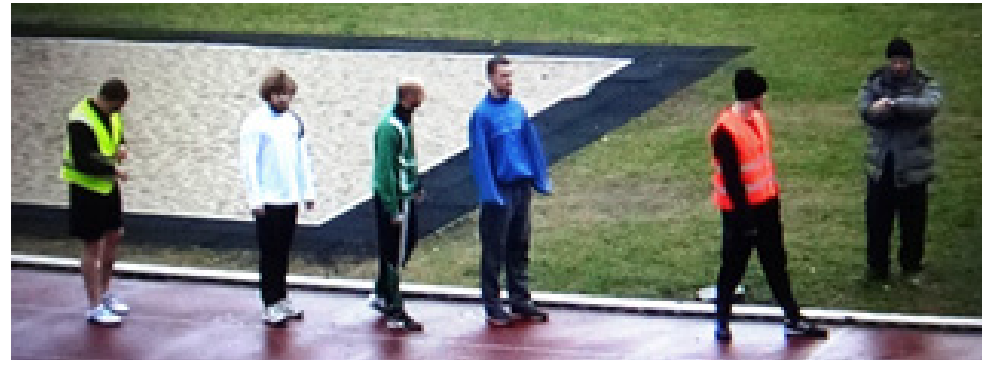

A

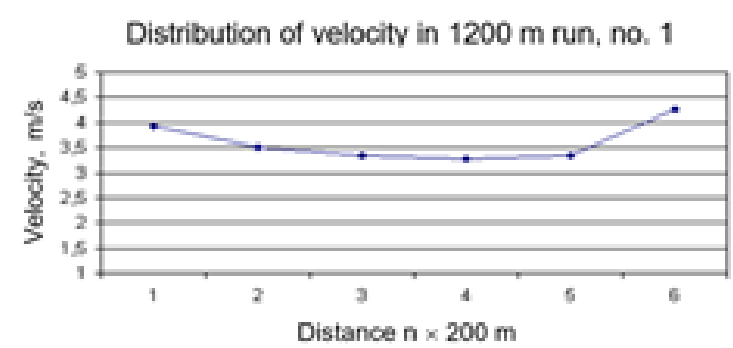

Figure 3 Research activities at the stadium of distribution of velocity at a distance of I $200 \mathrm{~m}: \mathrm{A}$ - students waiting for the start command at every 20 s; B - a diagram with gathering time at every $200 \mathrm{~m}$ (times were obtained with the video camera). Students had heart beat sensor in order to check their involvment into the run. It was found the involvment was high. ${ }^{27}$

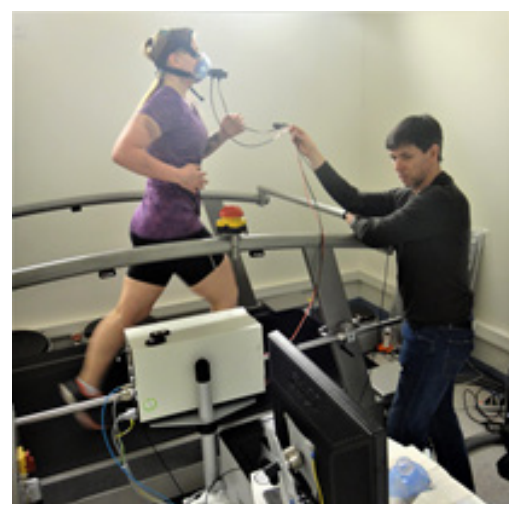

A

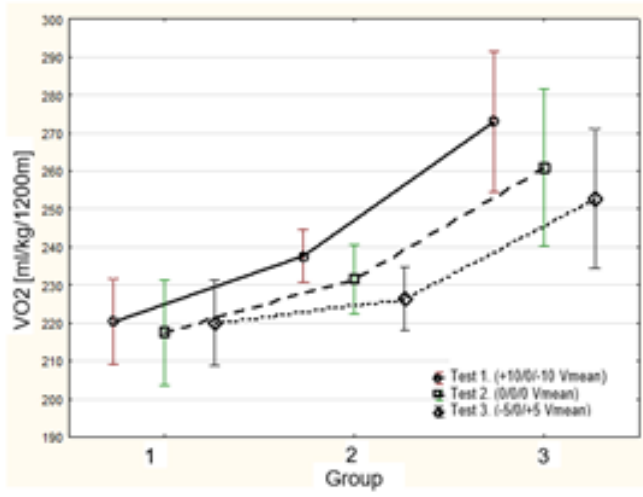

B

Figure 4 Laboratory investigations of distribution of velocity at a distance of $1200 \mathrm{~m}: \mathrm{A}$ - a subject runs on a treadmill; B - diagram of oxygen consumption by three groups; better at left), medium, worse (at right) when they ran with different distribution of velocity with the same average value of velocity. ${ }^{28}$ 


\section{Biomechanics of speed skating (long track)}

Since many years Gdansk biomechanists are engaged in research of winter sports: alpine and cross-country skiing and lately in speed skating at the long track. At the end of 2018 we participated in research work during World Cup which took place in Ice Arena in Tomaszow Mazowiecki. In 2019 the first elaborations were presented during the scientific meeting (Figures 5\&6). ${ }^{29,30}$
A

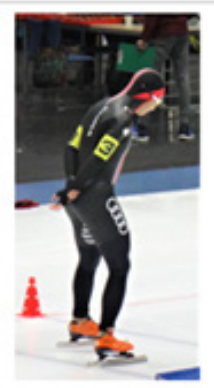

B

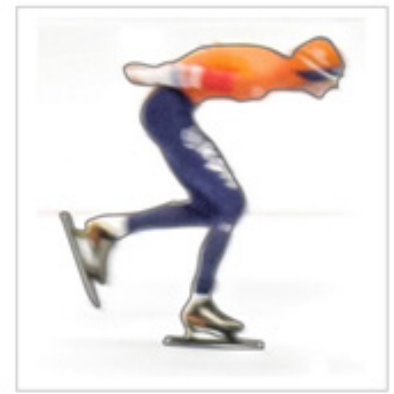

$\mathrm{C}$

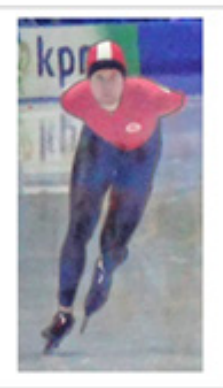

D

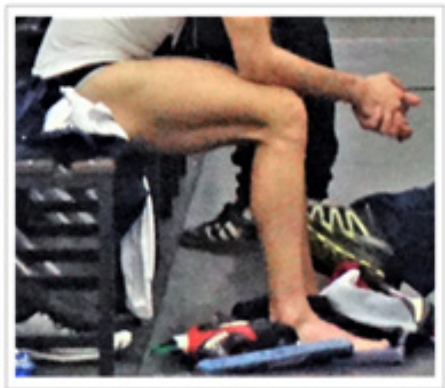

Figure 5 Biomechanical research of speed skating: A - slim body of a competitor, B and C - leaned body gives smaller frontal area, D - enormously enlarged quadriceps femoris muscle (athlete after the run). ${ }^{29}$

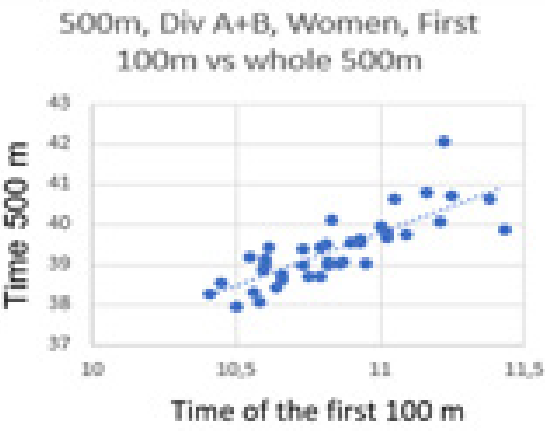

A

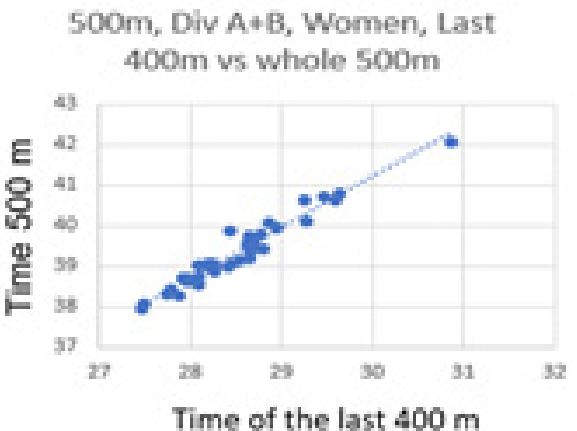

\section{$500 m$, Div A+B, Women, First $100 \mathrm{~m}$ vs whole $500 \mathrm{~m}$}

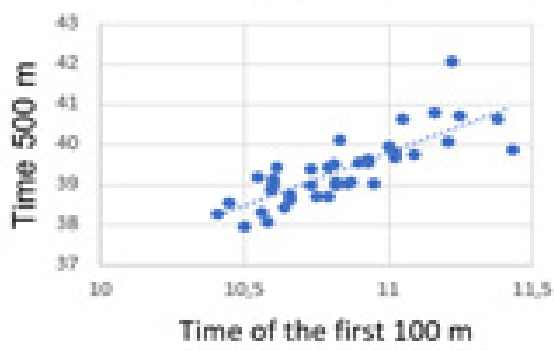

C

Figure 6 Investigations of distribution of velocity in speed skating:A - after the first $100 \mathrm{~m}$ it is hard to say who will be the winner in $500 \mathrm{~m}$ distance; B - further fragment shows strong correlation of time with the end time; $\mathrm{C}$ - the male winner at $10 \mathrm{~km}$ had rising velocity profile along the distance (this is in accordance with the Erdmann's law on distribution of load); quasi-full = without the first $400 \mathrm{~m} \cdot{ }^{30}$

\section{Athletics' high jumping}

In 2019 an article was prepared for Journal of Biomechanics on inertial quantities - mass, location of centers of mass, especially five parts of the trunk, obtained based on individual anthropologicalbiomechanical measurements of fit, young subjects. They were control group to high jumpers. ${ }^{31}$ Beyond this Erdmann prepared Report on high jumping in which he included several research activities of this athletics discipline, and also analyses of jumps of the competitors: a) Richard D. Fosbury from USA (innovator of flop technique), b) Javier Sotomayor from Cuba (world record holder, $245 \mathrm{~cm}$ ), c) Stefan Holm from Sweden (being $180 \mathrm{~cm}$ tall he cleared the bar at the height of $240 \mathrm{~cm}$ ), d) Mutaz E. Barshim from Qatar (actually the best world high jumper, his personal best is $243 \mathrm{~cm}$ ). Barshim has a Polish coach, namely Stanisław (Stanley) Szczyrba. Erdmann met him at the IAAF World Championships in October 2019 in Doha (Qatar). After returning home Erdmann has sent to him and to Qatar Athletics Federation a Report on high jumping. The Report has been also sent to the Polish Athletics Union (Figure 7). ${ }^{32}$ Within some world elaborations location of center of mass when an athlete is over the bar, is presented substantially (up to about $25 \mathrm{~cm}$ ) below the bar, which is wrong.

\section{Forensic biomechanics}

Since 1994 Erdmann elaborated more than ten expert opinions for the needs of justice institutions (courts, prosecutors, military police). Such opinions with taking into account hitherto existing legal proceedings (selected problems having connections with the opinion), visit to the scene of the incident, often with the conducting of procedural experiment, are written on tens of pages. In 2019 the following opinions were commissioned to Erdmann: a) for the need of Regional Prosecutor in Legnica (the case was about deadly accident of the pupil during cross country lesson; pupil was guilty of the wrong doing) $;^{33} \mathrm{~b}$ ) for the need of Regional Court in Ilawa (the case was on payment of Guarantee Insurance Fund for the victim of the car accident; it was said that healthy person is a fit person and the victim of an accident should be paid large amount of compensation because she will never be fit).$^{34}$ At the end of 2019 Erdmann gathered few opinions from the area of physical culture and presented them together during scientific meeting. ${ }^{35}$

\section{Closing remarks and conclusion}

Altogether research activities of the Laboratory of Biomechanics and Sport Analytics and Engineering of the Gdansk University of Physical Education and Sport encompass almost 30 scientific areas: ${ }^{36}$

i. Geometry of the body - external and internal

ii. New method of investigation of body inertia - analyzing body layers with CT or NMR

iii. Improved method of investigation of muscle strength in statics - not only obtaining of moment of force but also calculation of muscle strength 
iv. New method of recording and analyzing sport games - with one camera and wide-angle lens analyzing of individual players, formations and the whole team's kinematics

v. New method of investigation of alpine skiing course's run at the whole distance by obtaining geometry of the whole giant slalom and other disciplines, video recording of the run in order to obtain time between gates and calculating velocity

vi. Distribution of load/velocity in time and along the distance

vii. Systematics of biomechanics

viii. History of biomechanics

ix. Biomechanics of sport - general

x. Biomechanics of athletics - race walking, running, high jumping

xi. Biomechanics of judo

xii. Biomechanics of team handball

xiii. Biomechanics of football/soccer

xiv. Biomechanics of alpine skiing xv. Biomechanics of cross-country skiing

xvi. Biomechanics of speed skating

xvii. Biomechanics of swimming

xviii. Biomechanics of rowing

xix. Systematics of sport

xx. Sport analytics

xxi. Geography of sport

xxii. Image methods of sport research

xxiii. Systematics, description and new devices of sport engineering

xxiv. Systematics and description of engineering of movement rehabilitation

xxv. Systematics of kinesiology

xxvi. Biomechanics of astronautics

xxvii. Photogrammetry - photography for biomechanical purposes

xxviii. Expertise opinions for legal institutions in the area of accidents

xxix. Tourism in seashore areas

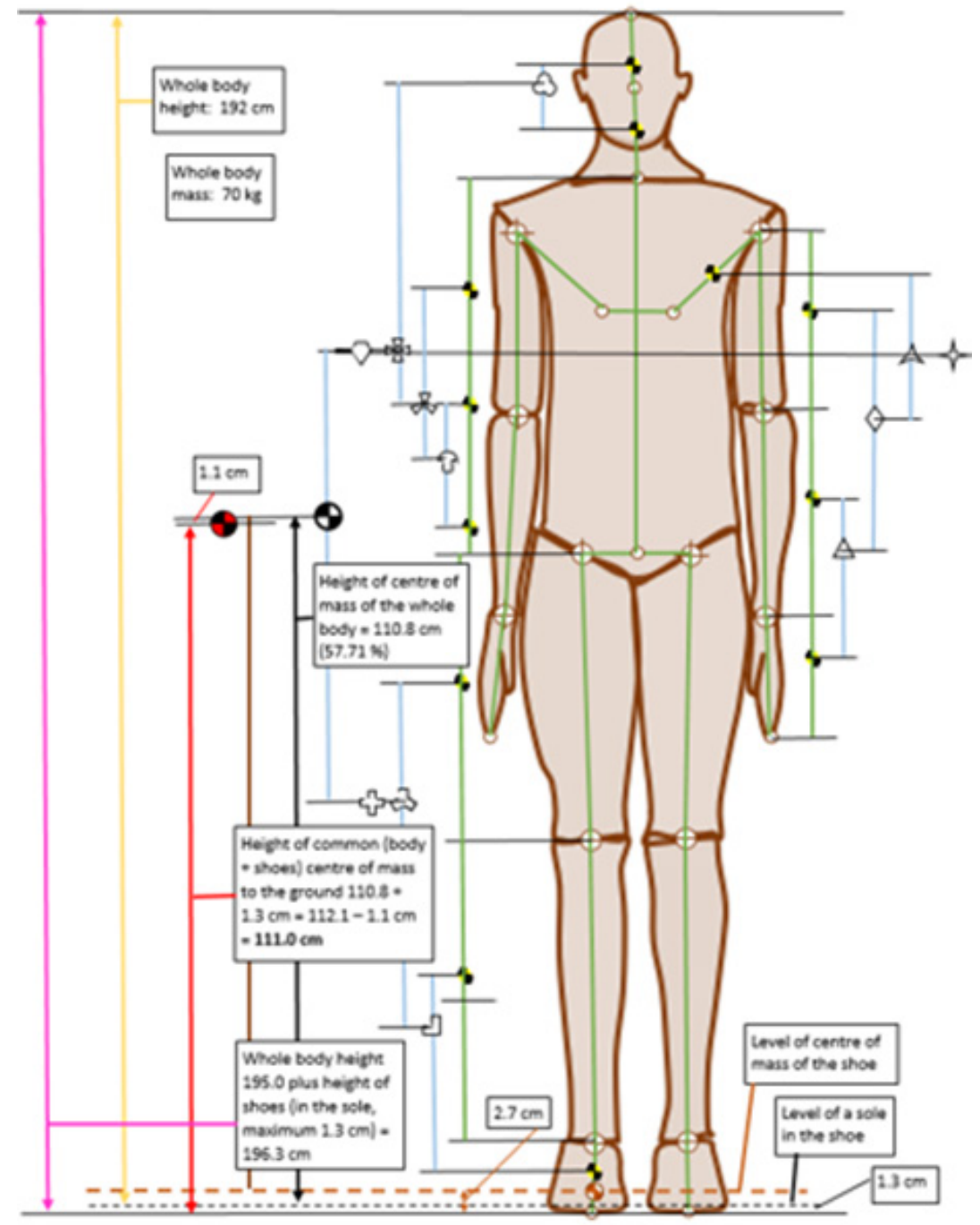

Citation: Erdmann WS, Aschenbrenner P, Dancewicz-Nosko D, et al. University laboratory of biomechanics and sport analytics and engineering in Gdansk as an important science institution. MOJ App Bio Biomech. 2020;4(I):8-I3. DOI: I0.I5406/mojabb.2020.04.00 I 24 

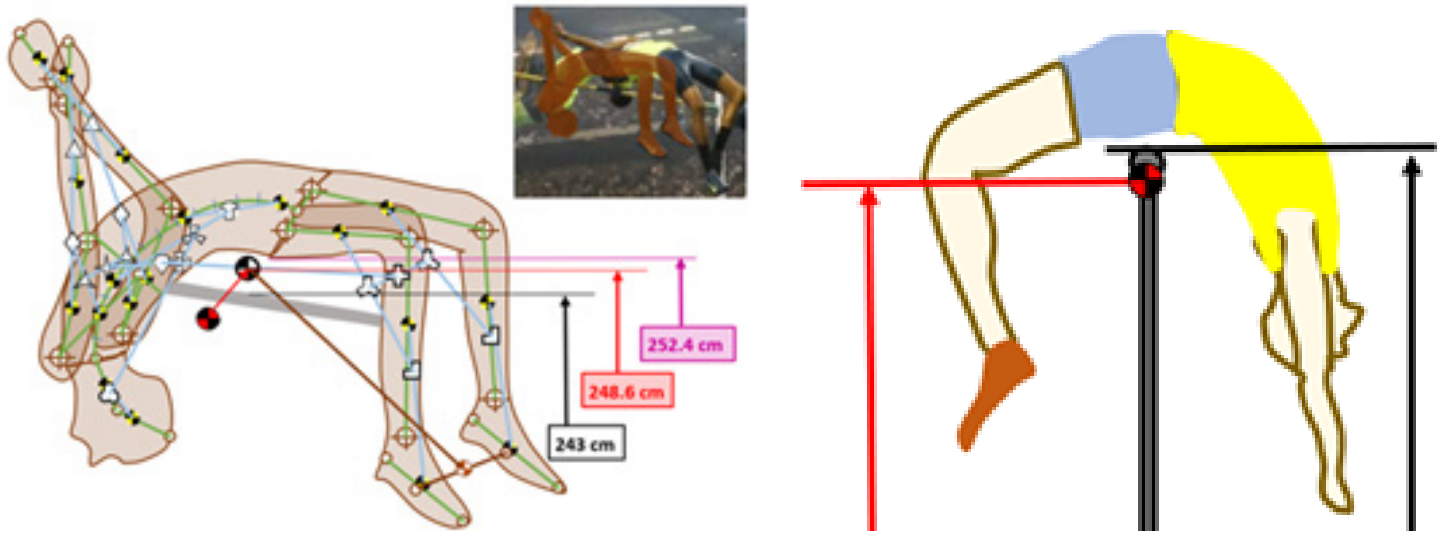

Figure 7 Research on high jumping - location of center of mass during upright standing (A) and during clearing the bar (B) by Mutaz E. Barshim. While the sport world record holder is Javier Sotomayor $(245 \mathrm{~cm}$, he bent a bar a little bit), so biomechanical world record holder is Mutaz E. Barshim (252 $\mathrm{cm})$. Center of mass (red line) was located together with his shoes. C - proposition of Erdmann's technique of high jumping with upper extremities below the head (black color - position of the bar, red - position of center of mass). ${ }^{32}$

Above mentioned areas of scientific interests are mostly on the world level and many of them are developed on the best world level. Professor Julian Hong, president of the International Society of Biomechanics in Sports, considered Erdmann as one of the leading biomechanists in the world. ${ }^{37}$

In conclusion it can be said this article plays a role as information on what was done in the example of Central Europe laboratory devoted to biomechanics, sport, engineering. It is a forum of exchanging information with other scientific circles all over the world. It is also an invitation to possible cooperation between scientists from different parts of the world.

\section{Acknowledgements}

None.

\section{Conflicts of interest}

The authors declare, that there is no conflict of interest.

\section{Funding}

None.

\section{References}

1. Aristotle. On the Motion of Animals. Transl. by Farquharson ASL. 2004.

2. Borelli A. De Motu Animalium. Lugduni Batavorum (Leiden): Petrum Vander; 1680.

3. Muybridge E. Animal locomotion. Pittsburgh: University of Pennsylvania A selection of plates appeared as: Muybridge E. Human Figure in Motion. An Electro-Photographic Investigation of Consecutive Phases of Muscular Actions. London: Chapman \& Hall; 1887.

4. Marey JE. Movement (in French). New York: D. Appleton and Company; 1895.

5. Erdmann W. S. (2004) Feliks Kaminski-pioneer of biomechanics in Poznan University of Physical Education (in Polish). Physical Education and Sport, 48:295-297.

6. Majewski T. Roman Poplewski 1894 -1948. In: Salwa P, Wroblewski AK, editors. Portraits of Scientists: Professors of the Warsaw University 1915-1945. Monumenta Universitatis Varsoviensis 1816-2016. 2016. p. 128-132.
7. Kabsch A. Biomechanical analysis of some skiing elements in persons after amputations. Poznan: University of Medicine; 1961.

8. Fidelus K. Biomechanical parameters of human upper extremities (in Polish). Research Yearbook, Vol. XV, Warsaw: University of Physical Education; 1971.

9. Bober T. Biomechanical assumptions of technique training (in Polish). Scientific Proceedings, vol. X, Wroclaw: University of Physical Education; 1973.

10. Wit A. Problems of regulation in the process of development of muscle strength on the example of athletes practicing weightlifting (in Polish). Warsaw: University of Physical Education; 1980.

11. Dworak LB. Natural trend of strength of selected muscle groups in ontogenesis of children and youth of large city population (biomechanical inspirations) (in Polish). Monographs, Scripts, Handbooks, no. 283, Poznan: Piasecki University of Physical Education; 1990.

12. Erdmann WS. Biomechanics: fundamentals for biomedical engineering major (in Polish). Gdansk: Gdansk Technical University; 2015.

13. Erdmann WS, Zieniawa R. Biomechanics of judo (in Polish). Gdansk: Gdansk University of Physical Education and Sport; 2011.

14. Erdmann WS. Image Methods: research on technique, tactics, time and distance in sports from prehistory up to 21 st century (in Polish). Gdansk: Gdansk University of Physical Education and Sport; 2006.

15. Erdmann WS. Engineering of movement rehabilitation (in Polish). Gdansk: Gdansk Technical University; 2016.

16. Erdmann WS, Gos T. Density of trunk tissues of young and medium age people. J Biomech. 1990;23(9):945-947.

17. Erdmann WS. Geometric and inertial data of the trunk in adult males. $J$ Biomech. 1997;30(7):679-688.

18. Erdmann WS, Kowalczyk R. A personalized method for estimation centre of mass location of the whole body based on differentiation of tissues of a multi-divided trunk. J Biomech. 2016;48(1):65-72.

19. Aschenbrenner P. Kinematics of running of competitors of the alpine skiing giant slalom course and its geometrical parameters (in Polish). Doctoral dissertation, Gdansk: Gdansk University of Physical Education and Sport; 2002.

20. Dargiewicz R. Playing of football at different levels of sport mastery in the light of kinematics analysis (in Polish). Doctoral dissertation, Gdansk: Gdansk University of Physical Education and Sport; 2005. 
21. Erdmann WS. Application of biomechanics in soccer training. In: Bartlett R, Hong Y. editors. Routledge Handbook on Biomechanics and Human Movement Science. London; New York: Routledge, Taylor and Francis Group; 2007. p. 525-537.

22. Kowalczyk R. Localization of center of mass of high jumpers and configuration of the body according to the bar (in Polish). Doctoral Dissertation, Gdansk: Gdansk University of Physical Education and Sport; 2013.

23. Urbanski R. Distribution of velocity at the distance and results of competition of multi-squad rowing crews (in Polish). Doctoral Dissertation, Gdansk: Gdansk University of Physical Education and Sport; 2017.

24. Erdmann WS. Geometry and inertia of the human body. Acta Physica Polonica A. 2019;135:961-964.

25. Erdmann WS. Geometry and inertia of the human body and their sport ap plications. In: Furst D, editor. A Closer Look at Biomechanics. Hauppauge, NY, USA: Nova Science Publishers; 2019. p. 99-132.

26. Erdmann WS. Conception of a biological law of distribution of a load during long term activities. Scientific meeting of the Chair of Natural Sciences, Faculty of Physical Education, Gdansk: Gdansk University of Physical Education and Sport. 2009.

27. Erdmann WS, Urbanski R, Aschenbrenner P, et al. Distribution of running velocity of young fit adults: preliminary description. In: Arkusz K, Bedzinski R, Klekiel T, editors. International Conference of the Polish Society of Biomechanics "Biomechanics 2018". Abstracts Book [two pages], 5-7 September 2018, Zielona Gora, 2018. p. 77-78.

28. Urbański R, Erdmann WS, Aschenbrenner P. Research on distribution of velocity and effort of the organism based on oxygen consumption during running of students of physical education major (in Polish). In: Urbanik Cz, editor. Jubilee 10th Symposium of Biomechanics of sport and Rehabilitation. 5-6.12.2019, Warsaw: J Pilsudski University of Physical Education; 2019. p. 70-71.
29. Erdmann WS. Basics of biomechanics of speed skating (long track): compendium (in Polish). In: Urbanik Cz, editor. Jubilee 10th Symposium of Biomechanics of sport and Rehabilitation. 5-6.12.2019, Warsaw: J Pilsudski University of Physical Education; 2019. p. 45-46.

30. Dancewicz-Nosko D, Erdmann WS. Competition of speed skating (long track) of World Cup Tomaszow Mazowiecki 2018: preliminary analysis (in Polish). In: Urbanik Cz, editor. Jubilee 10th Symposium of Biomechanics of sport and Rehabilitation. 5-6.12.2019, Warsaw: J Pilsudski University of Physical Education, 2019. p. 40-41.

31. Erdmann WS, Kowalczyk R. Basic inertial quantities including multi-segment trunk of fit, young males obtained based on personalized data. Sent to J Biomech. 2013.

32. Erdmann WS. Gdansk biomechanical report on high jumping: body centre of mass and the bar. Scientific Report. Gdansk: Gdansk University of Physical Education and Sport; 2019.

33. Erdmann WS. Opinion on deadly accident of the pupil during crosscountry training against the suspect T... P... in Legnica. For: Regional Prosecutor Office in Legnica, No. PR 3Ds 408.2018. 2019.

34. Erdmann WS. Biomechanical opinion in the case of K... Z... against Guarantee Insurance Fund in Warsaw for payment. For: Regional Court in Ilawa, No. I C 1464/17, 2019.

35. Erdmann WS. Selected biomechanical opinions for legal institutions in the area of physical culture. In: Urbanik Cz, editor. Jubilee 10th Symposium of Biomechanics of sport and Rehabilitation. 5-6.12.2019, Warsaw: J Pilsudski University of Physical Education; 2019. p. 42-44.

36. Aschenbrenner P. Half century (1969-2019) of professional activity of professor Wlodzimierz Stefan Erdmann. In: Urbanik Cz. editor. Jubilee 10th Symposium of Biomechanics of sport and Rehabilitation. 5-6.12.2019, Warsaw: J. Pilsudski University of Physical Education; 2019. p. 33-35.

37. Bartlett R, Hong Y. Routledge Handbook on Biomechanics and Human Movement Science. London, New York: Routledge Taylor and Francis Group; 2007. 